\title{
A ESCOLA DO CONSTRUCTIVISMO LÓGICO-SEMÂNTICO E OS LIMITES DA INTERPRETAÇÃO: UMA (RE)CONCEITUAÇÃO DO TRIBUTO NO BRASIL
}

Maria Lírida Calou de Araújo e Mendonça

Pós-doutora em Direito pela Universidade Federal de Santa Catarina - UFSC. Doutora em Direito pela Universidade Federal de Pernambuco - UFPE. Professora do Programa de Pós-Graduação em Direito Constitucional da Universidade de Fortaleza - UNIFOR. E-mail: liridacalou@unifor.br

Fernanda Mara de Oliveira Macedo Carneiro Pacobahyba Doutoranda em Direito Tributário pela Pontifícia Universidade Católica de São Paulo - PUCSP. Mestre em Direito Constitucional pela UNIFOR. Professora dos cursos de graduação e pós-graduação da Universidade de Fortaleza - UNIFOR. Auditora Fiscal Jurídica da Receita Estadual. E-mail: pacmara9@yahoo.com.br

\section{Resumo}

A questão em torno dos resíduos sólidos, problemática oriunda dos efeitos deletérios de uma sociedade de consumo, pós-industrial, pós-moderna, na qual se evidenciam riscos imprevisíveis, expóe a complexidade das relaçóes atuais e acaba por promover uma maior concatenação nas divisóes tradicionais dos ramos do Direito. Nesse ponto, vê-se que o estudo combinado do Direito Ambiental com o Direito Tributário faz-se mais do que necessário, especialmente ao se confrontar a gestão dos resíduos sólidos com a logística reversa. Diante disso, foi instituída a Política Nacional dos Resíduos Sólidos (PNRS), por meio da Lei no $12.305 / 10$, elencando um conjunto de princípios, objetivos e instrumentos para uma gestão integrada dos resíduos sólidos. Dentre os instrumentos previstos na PNRS, destaca-se a utilização de incentivos fiscais em atividades econômicas que se coadunem com o desenvolvimento sustentável, sendo este o objeto de investigação deste trabalho científico. A partir de uma pesquisa de natureza bibliográfica, descritiva e exploratória, verifica-se que o desenho dos incentivos fiscais na PNRS deve ser o mais amplo possível, em especial ao se tomar como paradigma o ICMS. Trata-se do tributo estadual mais importante e que tem revelado importantes vieses, ao serem estruturados incentivos fiscais que favorecem a implementação de sistemas de logística reversa. A partir de uma experiência adotada no Estado do Ceará, conclui-se que tal incentivo fiscal há de ser levado a discussão no âmbito do CONFAZ, visando a engajar outros entes federativos, com 
vistas a de alcançar resultados mais frutíferos de estímulo no gerenciamento dos resíduos sólidos pelas empresas brasileiras.

\section{Palavras-chave}

ICMS; PNRS; Incentivos Fiscais; Logística Reversa; Confaz.

\section{Abstract}

The question around the solid waste problem arising from the deleterious effects of a consumer society, post-industrial, postmodern, in which are evidenced unpredictable risks, exposes the complexity of current relationships and ultimately promote greater concatenation in the traditional divisions branches of law. At this point, it is seen that the combined study of Environmental Law with the Tax Law is now more than necessary, especially when comparing the solid waste management in reverse logistics. Thus was instituted the National Policy of Solid Waste (PNRS), by means of Law No. 12.305/10, listing a set of principles, objectives and instruments for an integrated solid waste management. Among the instruments within PNRS, we highlight the use of tax incentives in economic activities that are consistent with sustainable development, which is the subject of investigation of this scientific work. From a survey of literature, descriptive and exploratory nature, it appears that the design of tax incentives on PNRS should be as broad as possible, especially when taken as a paradigm of ICMS. This is the most important state tax and has revealed important biases, to be structured tax incentives that promote the implementation of reverse logistics systems. Starting a process in the state of Ceará experience, it is concluded that this tax incentive discussion is to be taken under the CONFAZ, aiming to engage other federal entities, with a view to achieve more fruitful results of stimulation in the management of waste solids by Brazilian companies.

\section{Key words}

ICMS; PNRS; Tax Incentives; Reverse Logistics; Confaz.

\section{Introdução}

Ao se estudar a forma como é pensado o Direito Tributário brasileiro, em especial sob o enfoque da Teoria Geral do Direito, percebe-se a existência de uma heterogeneidade de escolas distintas, que tentam abordar o fenômeno jurídico-tributário a partir de estruturas previamente dispostas. Tais abordagens, contudo, normalmente não respeitam os pressupostos científicos básicos e, sequer, conseguem apresentar cortes metodológicos consistentes e transparentes, além da indispensável coerência das fundamentaçôes. 
Uma das razóes para a superficialidade nas abordagens relativas ao Direito Tributário pode ser inferida a partir do reconhecimento de uma certa "juventude" desse ramo do Direito brasileiro, que vê raiar suas obras mais consistentes a partir do pensamento inovador e profundo de Alfredo Augusto Becker, o qual chega a denunciar o "carnaval" que se promovia para a consecução das atividades afetas à Administração Tributária.

A desordem (des)estruturada, denunciada nos idos da década de 1960, parece não ter tido fim ao se observar, na atualidade, a efusão de textos normativos que se sobressaem pela falta de conexão básica com o diploma fundamental do ordenamento jurídico brasileiro, qual seja, a Constituição Federal de 1988. Como exemplos gritantes no ordenamento, pode-se citar o Protocolo ICMS no 21, de $1^{\circ}$ de abril de 2011, bem como a cobrança do ICMS incidente sobre a importação de bens por pessoas físicas, conforme pretendeu a Emenda Constitucional no 33, de 11 de dezembro de 2001.

Contudo, para a tese que a partir daqui se pretende construir, interessa apontar um expediente metodológico denominado "Constructivismo lógico-semântico", o qual surge com a tese apresentada por Paulo de Barros Carvalho, no concurso para professor titular da Faculdade de Direito do Largo do São Francisco, intitulada "Direito Tributário - Fundamentos Jurídicos da Incidência”.

Tal instrumento de trabalho tem sido utilizado na construção de uma escola do Direito Tributário, cujo foco maior reside na Pontifícia Universidade Católica de São Paulo, que se propóe a identificar o fenômeno jurídico a partir da linguagem, assegurando-se da precisão dos termos utilizados e com uma especial atenção à estruturação sintática da frase. No entanto, não significa relegar a segundo plano o conteúdo, que será construído a partir do processo hermenêutico.

A partir do constructivismo lógico-semântico, pretende-se investigar o conceito fundamental do Direito Tributário, qual seja, o conceito de tributo, especialmente a partir da existência de dois diplomas legislativos distintos que pretendem conformar a matéria: a Lei no 4.320, de 17 de março de 1964, e a Lei no 5.172, de 25 de outubro de 1966, atualmente denominada Código Tributário Nacional. Tais leis serão confrontadas com as disposiçóes da $\mathrm{CF} / 88$, em especial a partir de identificação dos valores eleitos pelo constituinte, questionando acerca do signo "tributo".

Pode-se inferir que, diante da realidade da década de 1960, havia uma lógica que engendrava a instituição de tributos, com um forte conteúdo fiscalista e partindo-se de estruturas mais simplificadas tanto no que tange à lei, quanto ao se observar a forma como era realizada a arrecadação e a fiscalização.

Contudo, a partir da Constituição Federal de 1988, percebe-se que existe uma mudança no Sistema Tributário Nacional, com a incorporação das contribuiçóes e pela exploração de um discurso fortemente tendencioso a enxergar a extrafiscalidade em todas as 
espécies tributárias existentes. Ademais, não se pode olvidar que as leis tributárias nunca foram tão complexas, havendo uma divergência de interpretação tremenda entre aquilo que o fisco entende ser a regra-matriz dos tributos e o que os contribuintes enxergam nas mesmas normas jurídicas em sentido estrito.

Assim, o presente trabalho visa a promover uma reflexão da re(conceituação) do tributo em face do Constructivismo Lógico-Semântico, em especial a partir da delimitação de tal signo realizada nos idos de 1960, quando surge o primeiro pensamento científico acerca do Direito Tributário, e a investigação desse mesmo signo na atualidade, a partir das construçóes empreendidas pela escola capitaneada por Paulo de Barros Carvalho.

Dessa maneira, pretende-se indagar se, a despeito de não ter havido mudança nos textos legislativos que conceituam o tributo, teria ocorrida uma alteração em sua significação, a partir da promulgação da Constituição Federal de 1988, a qual traz um sistema normativo diferenciado em relaçáo ao anteriormente vigente, notadamente ao se levar em conta os valores aqui insertos e que funcionam como estruturadores das normas jurídicas que o intérprete constrói na atualidade.

Com tudo isso, o objetivo geral deste trabalho é analisar o potencial da linguagem, em seus inúmeros contextos de sentido construídos paulatinamente, como forma de reavivar o substrato normativo a cada nova interpretação. Tal atitude expressa o olhar de que se apropria a Escola do Constructivismo Lógico-Semântico, especialmente aqui utilizada sobre o conceito de tributo previsto no artigo $3^{\circ}$ do Código Tributário Nacional (CTN).

A metodologia utilizada é bibliográfica, descritiva e exploratória, a partir de uma elucidação da potencialidade dos sentidos gerados a partir do processo interpretativo, em especial ao se vislumbrar as propostas constructivistas, como método hábil a promover mudanças científicas profundas no conteúdo das normas jurídicas.

\section{O Paradigma da Linguagem e a Construção da Escola do Constructivismo Lógico-Semântico}

Ao se empreender um estudo mais aprofundado das teorias sobre o Direito, ainda não apontando especificamente para o Direito Tributário, percebe-se uma certa dificuldade em se identificar conceitualmente o seu objeto. Tal, contudo, deveria ser a preocupação primordial para aqueles que almejam defrontar-se com a ordem jurídica vigente. ${ }^{1}$

1 KELSEN, Hans. Teoria pura do direito. Tradução de João Baptista Machado. São Paulo: Martins Fontes, 2006, p. 33. 
Dessa forma, a partir de abordagens que pecam pela falta de identificaçáo no objeto de estudo, qual seja, o Direito, as concepçóes acerca da Ciência do Direito, concebida enquanto sistema, náo conseguem dar os contornos mínimos para os institutos que fundamentam-na enquanto ciência, desprezando o conteúdo metodológico e esbarrando em uma heterogeneidade de textos que não promovem uma "conversa" estruturada e coerente, que vise a revelar novos paradigmas e superar aqueles que estejam em descompasso com o discurso científico.

De tal defeito acaba padecendo, também, o Direito Tributário brasileiro. A uma, por ser um ramo relativamente incipiente do direito: a preocupação com o estudo científico do direito tributário surge a partir da década de 1960, com as obras de Alfredo Augusto Becker. Este estudioso asseverava que a doutrina, enquanto metalinguagem meramente descritiva, só seria verdadeira se vertesse, com neutralidade e imparcialidade, o direito positivo, o qual se configuraria em sua linguagem-objeto ${ }^{2}$.

A sobredita concepção se amoldava, com perfeição, às teorias de hermenêutica jurídica tradicionais, as quais se pautam no referencial da Filosofia da Consciência. A partir de tal modelo, a hermenêutica clássica propugnava pela existência de um sentido próprio dos textos positivados, a serem "revelados" pelo intérprete do direito ${ }^{3}{ }^{4}$. Nessa concepção, caso o texto se revelasse claro, cessaria o processo interpretativo.

Contudo, a partir do referencial filosófico do giro linguístico, a hermenêutica jurídica moderna não concebe mais um sentido a ser extraído do texto, como se nele estivesse entranhado: ao revés, o sentido há de ser construído, de acordo com os referenciais e com o contexto em que se vivencia. Aqui se insere o trabalho analítico-hermenêutico, o qual se processa em duas etapas: a primeira delas, compreende uma decomposiçâo analítica, com o fim de reduzir as complexidades e, a seguir, retoma-se a visão integral do fenômeno jurídico ${ }^{5}$.

2 FOLLONI, André. Ciência do Direito Tributário no Brasil: crítica e perspectivas a partir de José Souto Maior Borges. São Paulo: Saraiva, 2013, p. 16.

3 CARVAlHO, Aurora Tomazini de. Constructivismo lógico-semântico como método de trabalho na elaboração jurídica. In: CARVALHO, Paulo de Barros (coord.). Constructivismo lógico-semântico volume I. São Paulo: Noeses, 2014, p. 17.

4 Como exemplo da forma como é estruturado o processo interpretativo da Hermenêutica Tradicional, Paulo de Barros Carvalho cita Carlos Maximiliano Pereira dos Santos, para quem, o conteúdo do texto seria retirado do próprio texto, sendo o intérprete o responsável por descortinar o conteúdo que preexistia. Retirando uma citação da própria obra "Hermenêutica e aplicação do direito", do hermeneuta clássico, tem-se: "interpretar uma expressão do Direito náo é simplesmente tornar claro o respectivo dizer, abstratamente falando; é, sobretudo, revelar o sentido apropriado para a vida real, e conducente a uma decisão reta”. SANTOS, Carlos Maximiliano Pereira dos. Hermenêutica e aplicação do direito. Rio de Janeiro: Forense, 1997, p. 10.

5 TOMÉ, Fabiana Del Padre. Teoria do fato jurídico e a importância das provas. In: CARVALHO, Paulo de Barros (coord.). Constructivismo lógico-semântico - volume I. São Paulo: Noeses, 2014, p. 325326. 
Ainda no tocante ao giro linguístico ${ }^{6}$, Paulo de Barros Carvalho ${ }^{7}$ explica a relação entre o sujeito, o objeto e a possibilidade de o sujeito captar a realidade do objeto, o que levou, nesse movimento filosófico, a uma desconstruçâo da verdade objetiva e a uma tomada de consciência dos limites do ser humano. Nesse ponto, continua o autor, fundamentado no princípio da auto-referencialidade da linguagem, exsurge o movimento que se realiza a partir da retórica, não como singelo domínio de técnicas de persuasão, mas como o modelo filosófico adequado para a compreensão do mundo.

A partir dessa mudança paradigmática e tendo por base os estudos de Lourival Vilanova, o professor Paulo de Barros Carvalho apresenta uma primeira aplicação de um modelo intitulado "constructivista", o qual mantém uma relação aproximada da Teoria Comunicacional do Direito. Esta teria uma abrangência maior, aproximando-se mais de uma concepção filosófica, enquanto aquela se assemelharia a um método que visasse a outorgar a firmeza necessária ao discurso, tendo em vista a coerência e o rigor da mensagem comunicativa ${ }^{8}$.

Em assim sendo, a firmeza de que carece o discurso, de que falava Lourival Vilanova, associada a uma hermenêutica jurídica moderna, em que o intérprete tem o papel de construtor da norma jurídica, faz ressaltar a importância da adoção de um referencial filosófico, com vistas a tentar fincar bases sólidas para a teoria que se constrói. Assim, o estabelecimento da remodelação de velhos conceitos e a quebra de paradigmas tornam-se medidas necessárias para enfrentar os novos riscos e desafios que se póem à vida em sociedade, notadamente a partir de uma mudança nos conceitos básicos do Direito 9 e de todo o eixo individualista, formalista e cartesiano que ainda rege tal ciência.

\section{Aspectos em Torno da Visão do Direito pela Escola do Constructivismo Lógico-Semântico}

A partir da opção da (re)conceituação do tributo pelo viés da Escola do Constructivismo Lógico-Semântico, faz-se necessária uma breve reflexão acerca do conhecimento

6 Cite-se, ainda, a abordagem acerca da questáo do conhecimento empreendida por Fabiana Del Padre Tomé, na qual aponta como marco inicial da filosofia da linguagem a obra de Wittgenstein, empreendendo profunda digressão acerca do conhecimento, da verdade e do direito. TOMÉ, Fabiana Del Padre. A prova no direito tributário. Sáo Paulo: Noeses, 2011/2012.

7 CARVALHO, Paulo de Barros. Direito tributário: linguagem e método. São Paulo: Noeses, 2009, p. 160.

8 CARVALHO, Paulo de Barros. Algo sobre o constructivismo lógico-semântico. In: CARVALHO, Paulo de Barros (coord.). Constructivismo lógico-semântico - volume I. São Paulo: Noeses, 2014, p. 6.

9 Como pontua Gustavo Tepedino, após o longo processo de industrialização ocorrido na primeira metade do século XX, "verifica-se a introdução, nas Cartas políticas e nas grandes Constituiçōes do pós-guerra, de princípios e normas que estabelecem deveres sociais no desenvolvimento da atividade econômica privada". Nesse movimento, o Código Civil brasileiro perde o seu papel tradicional, não se voltando tanto para o indivíduo, mas para as atividades por ele desenvolvidas e os riscos dela decorrentes, ao mesmo tempo em que são enaltecidos os princípios e normas insertos na Constituição. TEPEDINO, Gustavo. Temas de Direito Civil. Rio de Janeiro: Renovar, 2008. 
científico atual, para que empreenda o corte metodológico que interesse ao objetivo central do trabalho. Assim, ultrapassados os momentos iniciais de desenvolvimento científico, interessam aqui as tensôes produzidas a partir da revolução industrial do século XVIII, potencializadas pelo avanço técnico-científico e por uma indefinição no conceito de ciência.

É importante ressaltar, contudo, que a forma de raciocinar da Idade Média, em que se tem o homem no centro de todo o sistema, influencia decisivamente os contornos da ciência, na qual se achava que todo o conhecimento poderia ser captado e traduzido em prol da figura eminente que era o homem. Daí a aparente condição de certeza científica, a inquestionabilidade dos conceitos postos, a aparente abrangência do conhecimento, que parecia abarcar tudo o que se movesse sobre a Terra.

Dessa forma, de algo estático, inabalável, inquestionável, expressóes tipicamente dogmáticas, passa-se a ter, como característica fundamental da ciência, a falseabilidade. Como afirma João Alves Silva, "dogma é produto do espírito do Homem; 'falsificabilidadé é o que busca a ciência quanto às leis do mundo" ${ }^{10} \mathrm{E}$ isso altera, profundamente, o conceito de ciência.

A modernidade vem com toda a força, enquanto resultado do Iluminismo, proclamando, a partir de então, de forma mais incisiva, o racionalismo, o antropocentrismo clássico e o universalismo. Tal período remonta à concepção clássica da modernidade, identificando-a com a racionalização, havendo uma redefinição da modernidade como a relação entre razão e o sujeito, carregada de tensôes, assim como racionalização e objetivação, ciência e liberdade. ${ }^{11}$

Entretanto, apesar de superada a etapa medieval de forte dogmatismo, ainda se tem, na atualidade, uma absolutização dos "poderes" da ciência na sociedade moderna. Enquanto isso, deve-se admitir que o conhecimento, especialmente sobre o direito, nunca é desinteressado, mas sempre direcionado com vistas a sua aplicabilidade, o que faz ressaltar que, mesmo na teoria mais abstrata, há potencialmente uma manipulação com fatos ${ }^{12}$. Seja pela importância que o desenvolvimento científico e tecnológico tem nos países mais desenvolvidos, seja pela facilidade em concentrar riquezas em virtude do imenso mercado de consumo que se encontra disponível, o que importa é que, passadas as eras da fé e da racionalidade, vige a era do mercado.

10 SILVA, João Alves. Conhecimento científico: conceito, determinantes e limites. In: Temas de Epistemologia Jurídica. Volume II. VASCONCELOS, Arnaldo (coord.). ARAGÃO, Nílsiton Rodrigues de Andrade. VIANA, Renata Neris (orgs.). Fortaleza: Universidade de Fortaleza, 2009, p. 169.

11 TOURAINE, Alain. Crítica da modernidade. 4. ed. Petrópolis: Vozes, 1997.

12 VILANOVA, Lourival. Fundamento do Estado de Direito. In: Escritos jurídicos e filosóficos. Volume 1. Sẫo Paulo: Editora Axis Mundi IBET, 2003, p. 414. 
A ciência, entáo, enquanto teoria, deve captada a partir de um movimento para frente de toda a humanidade, com liberdade para ousar e ultrapassar as estruturas. Há de se destacar, ainda, que a ciência não comporta mais uma atitude de explicação superficial de seus fenômenos: sua atitude há de ser proativa, buscando potencialidades preditivas, a dizer, indicando as ocorrências possíveis dentro de um determinado contexto, passandose a falar dela como empreendimento ou processo criativo ${ }^{13}$.

Com tudo isso, cabe reforçar que o conhecimento científico não é dogma, mas, ao contrário, é fomentada pelo senso crítico. $\mathrm{O}$ "endeusamento" do conhecimento científico leva inúmeras pessoas a encerrarem discussóes exacerbadas ao simples argumento de que “a ciência já provou isso...”. Karl Popper já identificara o conhecimento científico com uma conjectura, só podendo se caracterizar como verdadeira ciência aquilo que pode ser refutado. Daí, não há que se falar em perenização do conhecimento científico, visto que é de sua própria natureza a instabilidade, a brevidade e a falseabilidade.

Para Kuhn, "ciência é a reunião de fatos, teorias e métodos reunidos nos textos atuais" ${ }^{14}$ e, conforme Ferraz Jr, "o termo ciência não é unívoco; se é verdade que com ele designamos um tipo específico de conhecimento, não há, entretanto, um critério único que determine a extensão, a natureza e os caracteres deste conhecimento". ${ }^{15}$

Por fim, quanto aos critérios de demarcação científica, Demo assim os enuncia: coerência (enquanto ausência de contradição no texto), sistematicidade (esforço em abranger o tema plenamente, sem a necessidade esgotá-lo), consistência (capacidade de resistir à contra-argumentação), originalidade (deve corresponder a uma inovação), objetivação (tratar a realidade como ela é) e discutibilidade (propriedade da coerência no questionamento). ${ }^{16}$

Assim, se a cientificidade hoje decorre da possibilidade de falseamento ou do caráter não dogmático do conhecimento, consistindo nos caracteres da relatividade e da provisoriedade, não há porque não se atribuir tais características ao estudo do Direito, ${ }^{17}$ que também é ciência, e que se contamina pela incerteza. Se não há pretensão a ser verdade absoluta, faz parte do conhecimento científico, enquanto imprecisão, a presença do erro. Afirma Moles, então, que "os mais vagos domínios do conhecimento são, por isso, os mais sujeitos ao erro, pois o falso só aparece neste caso como tal após uma sequência mais longa de procedimentos". ${ }^{18}$

13 VASCONCELOS, Arnaldo. Teoria pura do Direito: repasse crítico de seus principais fundamentos. Rio de Janeiro: GZ Editora, 2010, p. 212.

14 KUHN, Thomas S. A estrutura das revoluçóes científicas. Tradução de Beatriz Vianna Boeira e Nelson Boeira. São Paulo: Perspectiva, 2001, p. 20.

15 FERRAZ JUNIOR, Tercio Sampaio. Direito, retórica e comunicaçáo. São Paulo: Malheiros, 1997, p. 43.

16 DEMO, Pedro. Metodologia do conhecimento científico. São Paulo: Atlas, 2000, p. 27-28.

17 MACHADO SEGUNDO, Hugo de Brito. Fundamentos do Direito. São Paulo: Atlas, 2010, p. 117.

18 MOLES, Abraham A. As ciências do impreciso. Tradução de Glória de Carvalho Lins. Rio de Janeiro: Civilização Brasileira, 1995, p. 299-300. 
Com tudo isso, faz-se necessário esse olhar sobre a modernidade que permita ousar diante das estruturas postas e abrir espaços na Ciência do Direito Tributário que seriam impensáveis tradicionalmente. Para finalizar, destaca-se que essa nova possibilidade há de ser empreendida como o fogo roubado por Prometeu e dado aos homens para que estes fiquem de pé, como os deuses, incitando-os a um projeto novo, mais do que os precipitando na temporalidade da utopia. ${ }^{19}$

Isto posto, a utilizar-se do constructivismo lógico-semântico, algumas premissas devem ficar bem esclarecidas. A primeira delas é a de que o Direito se apresenta como um sistema normativo que tem por objetivo regular a conduta humana, podendo ser identificados dois planos com o mesmo nome: (i) direito como conjunto de normas; e (ii) Direito como asserçôes sobre o Direito tomado como conjunto de normas ${ }^{20}$.

Em assim sendo, com o fito de regular condutas humanas, o direito empreende tal tarefa por meio da linguagem ${ }^{21} 22$, entendida esta como "uma faculdade humana abstrata, ou seja, uma capacidade: isto é, aquela capacidade que o humano tem de comunicar-se com os semelhantes por meio de signos mediante mecanismos de natureza psicofisiológi$\mathrm{ca}^{\prime 23}$. Assim, tal linguagem do direito dirige-se ao mundo social, buscando cristalizar fatos a partir de meras ocorrências de eventos, e registrando as provas necessárias a que surjam os fatos jurídicos.

Voltando às premissas, adotar-se-á uma posição normativista do direito, o que faz configurar que este deva ser entendido como o conjunto de normas válidas em um determinado país. Em concatenação com a primeira premissa, admitindo-se que o direito

19 OST, François. O tempo do direito. Tradução de Élcio Fernandes. Bauru: EDUSC, 2005, p. 192-193.

20 IVO, Gabriel. O direito e a inevitabilidade do cerco da linguagem. In: CARVALHO, Paulo de Barros (coord.). Constructivismo lógico-semântico - volume I. São Paulo: Noeses, 2014, p. 17.

21 Vale citar importante abordagem de Raimundo Bezerra Falcão, ao discorrer acerca do sentido, linguagem e direito: "Em outros enfoques, as relaçóes entre linguagem, sentido e Direito continuam evidentes. (...) Sem linguagem, a vida social e, por extensão, a vida político-jurídica tornar-se-iam impossíveis. Aristóteles já o assinalara, dizendo que o homem é um animal cuja vida se desenrola na comunidade política. E, se é em comunidade, tem de haver comunicação. Mas, para haver comunicação, a linguagem é imprescindível”. FALCÃO, Raimundo Bezerra. Hermenêutica. São Paulo: Malheiros, 2004, p. 79.

22 Conforme pontua Manfredo A. de Oliveira, "o escrito mais tardio que a Tradição nos legou em nossa cultura ocidental como reflexão sobre a linguagem ou, para usar uma expressáo de hoje, como crítica da linguagem é precisamente o Crátilo de Platão, escrito presumivelmente no ano 388 a. C. De antemão, é necessário considerar dois aspectos muito importantes: em primeiro lugar, Platấo toma aqui posição em relação a uma pergunta que realmente surge no início de qualquer consideração sobre a significação linguística, que é: por meio de que uma expressáo adquire sua significação? Em segundo lugar, respondendo a esta pergunta, Platão toma posição a respeito da essência da linguagem humana, que se tornou a concepção fundamental da linguagem no Ocidente, da qual hoje, com muito esforço, estamonos libertando. Ela se tornou mesmo a concepção de linguagem do "senso comum" do homem ocidental, legitimado pelos diferentes sistemas filosóficos”. OLIVEIRA, Manfredo A. Reviravolta linguísticopragmática na filosofia contemporânea. São Paulo: Ediçóes Loyola, 2006, p. 17-18.

23 BASTOS, Cleverson Leite; CONDIOTTO, Kleber B.B. Filosofia da linguagem. Petrópolis: Editora Vozes, 2007, p. 15. 
é linguagem, então as normas jurídicas são, antes de qualquer outra inferência, uma manifestação da linguagem: onde houver normas, há linguagem, o que, no Brasil, aponta necessariamente para uma linguagem escrita ${ }^{24}$.

A seguir, outra premissa subjaz importante de se referenciar: o direito é finalístico, sendo criado para disciplinar condutas intersubjetivas, canalizando-as em direção aos valores eleitos pela sociedade. É, reconhecidamente, um produto cultural ${ }^{25}$. Ademais disso, configura-se como objeto cultural ${ }^{26}$, que se caracteriza por existir no tempo e no espaço, estando na experiência do sensível e que deve ser captado pela compreensão: aqui se situa também a norma jurídica como objeto cultural, posto que, com ela, o homem altera a sua própria conduta, limitando a liberdade inerente à natureza humana ${ }^{27}$.

Tal natureza afigura-se também aproximada à moderna física quântica, para a qual "o ato de medir afeta o que está sendo medido" ${ }^{28}$. Nesse ponto, tem-se uma visão mais extremada ainda com os físicos Heisenberg e Born para quem as observaçóes náo apenas interfeririam no que estivesse sendo medido, mas produziriam o que está sendo medido ${ }^{29}$. Nesse ponto, então demonstra muita semelhança a física quântica com o constructivismo lógico-semântico, para o qual a linguagem cria o direito, cria a realidade.

Tomados tais pressupostos acerca da visão do direito pela Escola do Constructivismo Lógico-Semântico, faz-se necessário explorar, naturalmente, a diferença entre enunciado prescritivo e norma jurídica, posto que o direito, a seguir-se tal método, é tido como texto. Nesse diapasão, adota-se uma postura hermenêutico-analítica perante o objeto, a qual parte da decomposição do discurso jurídico.

\section{A Linguagem do Direito e seus Planos}

Conforme aduzido amplamente, se o direito é linguagem, parte-se do texto normativo qualquer análise que se pretenda jurídica. Nesse ponto, conforme aduz Gabriel Ivo, "as palavras nem sempre conseguem exprimir o conteúdo semântico do nosso pensamento. Por isso, sob o rótulo de norma jurídica, a produção do direito tem como objeto vários elementos: o documento normativo, (...); os enunciados prescritivos; e as normas jurídicas"30.

Em assim sendo, interessa aqui identificar como ponto de partida para o estudo da produção do direito o próprio documento normativo, sendo o enunciado pertencente ao

24 CARVALHO, Aurora Tomazini de, op. cit., p. 19.

25 CARVALHO, Aurora Tomazini de, op. cit., p. 20.

26 BELCHIOR, Germana Parente Neiva. Hermenêutica jurídica ambiental. São Paulo: Saraiva, 2011, p. 160.

27 FALCÃO, Raimundo Bezerra. Hermenêutica. São Paulo: Malheiros, 2004, p. 16-17.

28 GLEISER, Marcelo. A ilha do conhecimento. Rio de Janeiro, São Paulo: Record, 2014, p. 231.

29 Op. cit., p. 231.

30 IVO. Gabriel. Norma jurídica: produçáo e controle. São Paulo: Noeses, 2006, p. XXI. 
plano de expressão do direito, forma inicial de sensibilização daquele que pretenda ingressar no estudo do Direito. Segundo Lourival Vilanova, ao tratar do conceito de proposiçã̃o, as quais representam "asserçóes do que é algo, de que tal objeto tem a propriedade tal" 31 , alterar-se-ia o mundo social pela linguagem das normas, esta representando uma classe da qual é a linguagem das normas do Direito ${ }^{32}$.

Em assim sendo, o texto legislado, ou os suportes físicos, são apenas a "porta de entrada" para que se possa, ao final, alcançar a integralidade do sistema jurídico normativo, sendo a interpretação algo essencial neste contexto. No que tange ao processo interpretativo, Lourival Vilanova aduz que "interpretar é atribuir valores aos símbolos, isto é, adjudicar-lhes significaçóes e, por meio dessas, referências a objetos" ${ }^{33}$. Isto porque, as palavras não têm um significado ontológico, dado que é a própria linguagem que "cria" o objeto ${ }^{34}$.

Assim, conectando com a temática do presente estudo, o signo "tributo" não tem uma significação em si: esta é atribuída pelo intérprete, a depender de toda a carga valorativa de que esteja impregnado, isto é, de sua própria cultura. Isto porque, falar em direito é indissociável de falar dos valores ${ }^{35}$. Com isso, o processo interpretativo não se exaure, sendo algo infinito. Por isso, náo há como se entender o direito como algo estanque: interpretar acaba sendo um processo de construção do sentido normativo.

Deve-se ressaltar, apenas, que ao lidar com valores pertinentes à linguagem jurídica, identificados os fins que a circundam, o método analítico não é suficiente, havendo de ser pressuposta a hermenêutica. A partir desta, pode-se travar contato com os diversos sentidos dos textos normativos e com os referenciais culturais que os informam ${ }^{36}$.

Dito isto, a compreensão dos textos legislados passa por um trajeto gerador de sentido, representado por uma infinita reta em espiral que tem por base o suporte físico (texto escrito) e, em estrita conexão com os horizontes culturais do intérprete, alcança níveis de compreensão diferenciados, aqui representados pelos planos S1 (sistema da literalidade

31 VILANOVA, Lourival. As estruturas lógicas e o sistema de direito positivo. Săo Paulo: Noeses, 2010, p. 3.

32 Op. cit., p. 4.

33 VILANOVA, Lourival. Universo das formas lógicas e o direito. Escritos jurídicos e filosóficos. Volume I. São Paulo: IBET/Axis Mundi, 2003.

34 CARVALHO, Aurora Tomazini de. Curso de teoria geral do direito. São Paulo: Noeses, 2013, p. 224.

35 Aqui merece destaque a Teoria dos Valores, ou Axiologia, desenvolvida por importantes estudiosos dentro do Direito brasileiro, dentre eles, Miguel Reale, Tercio Sampaio Ferraz Júnior e Paulo de Barros Carvalho. Para este, "não é exagero referir que o dado valorativo está presente em toda configuração do jurídico, desde seus aspectos formais (lógicos), como nos planos semântico e pragmático. Em outras palavras, ali onde houver direito, haverá, certamente, o elemento axiológico". CARVALHO, Paulo de Barros. Direito tributário, linguagem e método. São Paulo: Noeses, 2009, p. 174.

36 CARVAlHO, Aurora Tomazini de. Constructivismo lógico-semântico como método de trabalho na elaboração jurídica. In: CARVALHO, Paulo de Barros (coord.). Constructivismo lógico-semântico volume I. São Paulo: Noeses, 2014, p. 23. 
textual), S2 (conjunto dos conteúdos de significação), S3 (sistema das normas jurídicas em sentido estrito) e S4 (plano da sistematização) $)^{37}$.

Deve-se fazer a lembrança, apenas, de que o direito positivo possui normas de conteúdo prescritivo, denotando algo que "dever-ser" 38 . Não obstante, algumas passagens das mensagens legisladas parecem desvirtuar desse apriori, parecendo denotar situaçóes meramente descritivas. Conforme lembra Aurora Tomazini de Carvalho, ao tratar de enunciados que aparecem sob a forma declarativa, deve o intérprete não se esquecer que lida com frases prescritivas, ainda que descrevam aspectos da vida social, ou acontecimentos naturais a ela relacionados ${ }^{39}$.

Contudo, ainda que a forma empregada pelo legislador não seja, sintaticamente, expressando um conteúdo que "deve ser", o intérprete, por se deparar com o sistema afeto ao direito positivo, deve resguardar o seu olhar consciente de tal realidade e colmatando o sistema de direito positivo com vistas a efetivar esse estado de coisas (de deve vir a ser).

Assim, o processo interpretativo há de iniciar-se a partir do plano $\mathrm{S} 1$, o qual expóe o primeiro contato que qualquer pessoa, provável intérprete, terá com o texto legislado. Tal plano é representado pelas marcas de tinta no papel, pela própria materialidade de qualquer expressão. Paulo de Barros Carvalho indica que é "a partir do contacto com a literalidade textual, com o plano dos significantes ou com o chamado plano da expressão, como algo objetivado, isto é, posto intersubjetivamente, ali onde estáo as estruturas morfológicas e gramaticais, que o intérprete inicia o processo de interpretação" ${ }^{40}$.

Trata-se, assim, da forma como os sentidos humanos são acionados e aguçados, notadamente a visão ou a audição ${ }^{41}$, sendo o passo inicial para que a compreensão possa ocorrer de modo satisfatório. A única ressalva que aqui se faz, no tocante a esse plano, diante de tantas observaçôes que poderiam ser feitas, refere-se à chamada interpretação literal, que não se coaduna com o movimento do giro linguístico pois parte de um conteúdo de base que seja ínsito a qualquer termo e que praticamente uniformizaria o resultado do processo interpretativo.

37 CARVALHO, Paulo de Barros. Direito tributário: fundamentos jurídicos da incidência. São Paulo: Saraiva, 2012, p. 105-123.

38 Acerca de tal temática, vale relembrar os escritos de Lourival Vilanova, acerca da "Analítica do dever-ser", os quais iniciam tratando esta expressáo como "dado imediato em nossa experiência com a linguagem do direito positivo”. VILANOVA, Lourival. Analítica do dever-ser. In: Escritos jurídicos e filosóficos. Volume 2. São Paulo: Editora Axis Mundi IBET, 2003, p. 45-92.

39 CARVAlHO, Aurora Tomazini de. Curso de teoria geral do direito: o constructivismo lógicosemântico. São Paulo: Noeses, 2013, p. 249.

40 Op. cit., p. 107.

41 E aqui jocosamente incluindo o sentido do paladar, para aquelas pessoas que são verdadeiros "comedores" de livros, em uma expressão alegórica para abarcar leitores vorazes. Já voltando-se, agora de maneira pertinente, ao caso dos cegos, há de se destacar os textos legislados que se apresentem em "Braile" ou símbolos conexos, que permitam a sua captação pelo tato. 
Diferentemente disso, não se apregoa aqui, em hipótese alguma, que a literalidade do texto seja satisfativa desse processo que culminará com a compreensão do texto legislado. Isso porque, a significação é construída pelo intérprete, de forma absolutamente individualizada e conectada às suas crenças e valores.

Partindo-se para o Plano S2, este representa a construção dos conteúdos significativos dos enunciados prescritivos apresentados no Plano S1. Ao dispor acerca desse plano, Aurora Tomazini de Carvalho explica-o como sendo aquele em que o sujeito cognoscente passa a lidar com "as significaçóes dos símbolos positivados", em verdadeiro ingresso no campo semântico, fazendo exsurgir toda a problemática que envolve o contexto jurídico ${ }^{42}$.

Alcançando o Plano S3, salta-se para o sistema em que é construída a mensagem jurídica, por meio da associação das proposiçóes elaboradas no plano S2 sob a forma hipotético condicional $(\mathrm{H} \rightarrow \mathrm{C})$ : dada uma hipótese, deve-ser o consequente. Aqui se introduz o conceito de norma jurídica enquanto "entidades mínimas dotada de sentido deôntico completo" ${ }^{43}$, com o fito de outorgar "unidade ideológica à conjunção de regras que, por imposiçáo dos próprios fins regulatórios que o direito se propóe implantar, organizam os setores mais variados da convivência social" ${ }^{44}$.

Por fim, ao ingressar no Plano S4, tem-se o modelo de estruturação, por coordenação e subordinação das normas sistematicamente organizadas. Trata-se de um campo especulativo muito rico, "pois é nele que o interessado estabelece as relaçóes horizontais e as graduações hierárquicas das significações normativas construídas no plano S3, cotejando a legitimidade das derivações e fundamentaçôes produzidas" ${ }^{45}$.

Neste plano, ainda, por investigar as relaçôes de subordinação e de coordenação, notadamente apontando para a Constituição Federal como o texto sobranceiro do ordenamento, é que são verificados eventuais vícios nas normas produzidas em que estejam em contrariedade com o diploma maior ou mesmo com leis que sejam hierarquicamente superiores. Quanto a essa estruturação em plano, há de se destacar de que não se trata de processo estanque e que siga, invariavelmente, a ordem seguida acima: definitivamente não. Isto porque, como a interpretação é inesgotável, tantas vezes quantas entender necessárias, deve o intérprete perpassar os planos, até que se dê por satisfeito na construção do sentido.

Ademais, tempos após ter encontrado a resposta que melhor satisfazia ao seu entendimento, diante de modificaçóes em seu próprio contexto cultural, pode o mesmo intérprete

42 Op. cit., p. 249.

43 CARVALHO, Paulo de Barros, 2012, op. cit., p. 67.

44 CARVAlHO, Paulo de Barros, 2012, op. cit., p. 120.

45 CARVALHO, Aurora Tomazini, 2013, op. cit., p. 256. 
retomar o procedimento, cogitando reanalisar cada um dos planos e apontar para uma compreensão completamente distinta. Isto porque, para a corrente filosófica que pela qual aqui se optou, na linha de Wittgenstein, a linguagem é considerada uma espécie de ação, de modo que aquela náo pode ser separada do agir humano, nem este pode ignorar a linguagem, pois, conforme Manfredo Araújo de Oliveira, "essa atividade se realiza sempre em contextos de ação bem diversos e só pode ser compreendida justamente a partir do horizonte contextual em que está inserida" ${ }^{46}$.

Nesse contexto, é mister refletir sobre a viabilidade de uma (re)conceituação do próprio tributo, daí se inferindo o caráter original da proposta, a partir do enaltecimento do seu papel finalístico quanto ao cumprimento dos desígnios constitucionais brasileiros, levando em conta o método analítico, redutor de complexidades para, a seguir, voltar-se para a hermenêutica, alcançando o plano $S 4$.

Por se tratar de reflexóes acerca dos tributos, deve-se fazer referência a que estes, na modernidade, seja qual for o regime econômico adotado pela nação, normalmente representam a principal fonte de receita ordinária do orçamento, e suas conceituaçóes têm variado conforme as épocas e os países, ${ }^{47}$ isto é, denota-se que o seu conceito é obtido a partir da consideraçáo do tempo e do lugar objeto de reflexáo.

Ao analisar de forma rápida a história dos tributos no Brasil, desde já buscando indícios dos mais diversos conceitos adotados ao longo do tempo, aduz-se que, apesar das controvérsias, entende-se que só se pode falar em legislação fiscal genuinamente brasileira a partir de 1822 . Desde a descoberta do país já se historia a cobrança dos tributos, contudo, tal cobrança se dava com base na legislaçáo portuguesa, que muito influenciou a legislação nacional que sobreviria. ${ }^{48}$

Entretanto, mais próximo ao atual momento constitucional inaugurado em 1988, deve-se fazer menção ao contexto que justificou a aprovação da Lei no 5.172 , de 25 de outubro de 1966. Trata-se de lei ordinária aprovada na vigência da Constituição de 1946, após o golpe militar de 1964, e que se justificou em virtude de uma maior preocupação econômica com o sistema tributário, sendo, até então, os tributos meramente escriturais, com fatos geradores estribados em contratos. ${ }^{49}$

Dessa forma, ao promover uma reforma estrutural significativa, o diploma acima, o qual viria a ser chamado de Código Tributário apenas em 14 de março de 1967, tendo

46 Op. cit., p. 138.

47 HUGON, Paul. O impôsto. Rio de Janeiro: Ediçóes Financeiras S.A., 1951, p. 15.

48 BALTHAZAR, Ubaldo Cesar. História do Tributo no Brasil. Florianópolis: Fundação Boiteux, 2005, p. 30-31.

49 Ibid., p. 132-133. 
sido recepcionado como lei complementar a partir da Constituição de 1967, ${ }^{50}$ é fundamental para o presente estudo por trazer aquele que é considerado o conceito de tributo até a atualidade.

Dessa forma, Hugo de Brito Machado afirma que, apesar de não ser papel da lei estabelecer conceitos, no tocante ao tributo, o CTN o fez expressamente, pois indica que o legislador, suplantando as divergências doutrinárias, admitiu a redação do CTN como definidora do tributo ${ }^{51}$. Na mesma esteira, Sacha Calmon destaca o primor no conceito de tributo no Direito Tributário brasileiro e que o mesmo desvenda a imposição tributária, a qual seria a pedra fundamental da disciplina ${ }^{52}$, a seguir transcrevendo na integralidade a redação do art. $3^{\circ}$ do CTN supratranscrita.

Em contrapartida, mas sem se apartar da doutrina tradicional, outra corrente amplia um pouco mais o conceito legal de tributo ao destacar a importância de seu assento constitucional, ressaltando que, por se tratar de transferência patrimonial da esfera privada para a esfera pública, poder-se-ia admitir que a tributação teria afetado ou reduzido o direito de propriedade. Contudo, pelo fato daquela também decorrer do mesmo poder constituinte, as dúvidas seriam dissipadas ${ }^{53} 54$.

Há, ainda, doutrina que defende que o conceito de tributo previsto na CF/88 incorporou aquele previsto no art. $3^{\circ}$ do CTN, afirmando-se que a norma constitucional teria adotado uma noção de tributo com os mesmos caracteres pré-definidos ${ }^{55}$, isto é, a partir do seu caráter pecuniário, da compulsoriedade, da instituição em lei, do fato de não decorrer da prática de ato ilícito, de que seja devido ao Estado ou a pessoa por ele delegada e observados os limites estabelecidos no próprio texto constitucional ${ }^{56}$.

Contudo, a partir da leitura dos diálogos contidos nos "Comentários ao Código Tributário Nacional”, em que Geraldo Ataliba, Rubens Gomes de Souza e Paulo de Barros Carvalho ${ }^{57}$ dialogam acerca da definição de tributo, intui-se que não há unanimidade

50 Ibid., p. 155.

51 MACHADO, Hugo de Brito. Curso de Direito Tributário. São Paulo: Malheiros, 2006, p. 76.

52 COÊLHO, Sacha Calmon Navarro. Curso de Direito Tributário Brasileiro. Rio de Janeiro: Forense, 2008, p. 422.

53 SCHOUERI, Luís Eduardo. Direito Tributário. São Paulo: Saraiva, 2011, p. 129.

$54 \mathrm{Na}$ mesma linha, Geraldo Ataliba, apesar de afirmar que o CTN conceitua tributo, aduz também que o conceito jurídico-positivo de tributo só pode ser construído a partir da observaçấo e análise das normas constitucionais. Acresce que a CF/88 "adota um preciso - embora implícito - conceito de tributo". ATALIBA, Geraldo. Hipótese de incidência tributária. São Paulo: Malheiros, 2008, p. 33.

55 CARRAZZA, Roque Antonio. Curso de direito constitucional tributário. São Paulo: Malheiros, 2013.

56 BARRETO, Paulo Ayres. Contribuiçóes: regime jurídico, destinação e controle. São Paulo: Noeses, 2006, p. 40.

57 SOUSA, Rubens Gomes; ATALIBA, Geraldo; CARVALHO, Paulo de Barros. Comentários ao Código Tributário Nacional. São Paulo: Quartier Latin, 2007, p. 54. 
quanto ao que representaria o enunciado do art. $3^{\circ}$ do CTN e, ao final, chegam à conclusão de que o preceito estaria mal formulado.

Entretanto, o que interessa destacar nessa ordem de ideias é o apego em se isolar o conceito de tributo no CTN, não se fazendo menção à ordem normativa vigente quando da edição da Lei no 5.172/66, nem se conectando com todo o arcabouço jurídico inovado a partir da CF/88. Nesse sentido, propóe-se investigar se a compostura do conceito de tributo pode vir pontilhada de providências no intuito de prestigiar certas situaçóes, tidas como social, política ou economicamente valiosas, às quais o legislador dispensa tratamento mais confortável ou menos gravoso.

Aqui, então, poder-se-iam apontar conjecturas acerca da extrafiscalidade, a qual, conforme Paulo de Barros Carvalho, representa um dos valores finalísticos que o legislador imprime na lei tributária, manipulando categorias jurídicas postas à sua disposição na perseguição de objetivos alheios aos meramente arrecadatórios. ${ }^{58}$

É importante destacar que, apesar de a extrafiscalidade ser uma fórmula jurídico-tributária para a obtenção de metas que prevalecem sobre os fins simplesmente arrecadatórios de recursos monetários, o regime que dirige referida atividade deve ser o próprio das exações tributárias. Deve o legislador guiar-se pelos parâmetros previstos na Constituição Federal, respeitando os limites da competência impositiva e dos princípios que regem a matéria.

Contudo, ao se observar os documentos normativos que instituem as diversas espécies tributárias, verifica-se que alguns deles apontam para uma nova tendência nas legislaçóes exacionais brasileiras. Como exemplos, podem ser citados os chamados "tributos ambientais", os quais têm um sentido estrito e um lato, conforme incidam em face da utilização direta do meio ambiente, ou em virtude de atos ou situaçôes apenas indiretamente a ele conexos.

Assim, em sentido estrito, tributo ambiental significa um tributo novo cobrado em razão do uso do meio ambiente pelos agentes econômicos, ou seja, seu fato gerador é uma situação que represente uma degradação ambiental em função do desempenho de uma atividade econômica lícita. Já em sentido amplo, tributo ambiental é um tributo tradicional ou ordinário adaptado de molde a servir aos esforços da proteção ambiental.

Especificamente quanto a esses tributos ambientais, a progressividade tributária vem sendo cogitada como uma ferramenta imprescindível na estruturação dos textos legais que instituem os tributos ambientais, sendo uma discriminação positiva entre poluidores e não poluidores. Nesse momento, questiona-se se a tributação ambiental não se estaria valendo da punição, haja vista que busca direcionar a conduta do meio social a partir de

58 CARVAlHO, Paulo de Barros. Curso de Direito Tributário. São Paulo: Saraiva, 2011, p. 290. 
gravames mais onerosos para atividades que poluam com maior intensidade, por exemplo. Ao revés, pode-se apontar que o tributo, nesse caso, estaria induzindo o contribuinte a planejar seu negócio lícito de acordo com uma finalidade pretendida pelo constituinte, no caso, a proteção ambiental.

No tocante a uma abordagem menos tradicional do conceito de tributo, a partir da sua utilizaçáo no contexto de crise ambiental, podem ser verificadas no Brasil muitos exemplos de legislaçóes que fazem a opção explícita pela extrafiscalidade, como é o caso da isenção de Imposto Territorial Rural (ITR) em relação às áreas de preservação permanentes (APP), de reservas legais (RL), bem como de outras áreas que a legislação aponta serem ambientalmente interessantes, conforme se verifica na Lei de Política Agrícola (Lei no 8.171/91) e na Lei no 9.393/96, que dispóe sobre o ITR.

A mesma lógica vem sendo utilizada por alguns municípios ao concederem descontos no valor do Imposto sobre a Propriedade Territorial Urbana (IPTU) aos contribuintes que possuam projetos que estejam contemplando construçóes que adotem técnicas sustentáveis e a favor do meio ambiente. ${ }^{59}$

Por outro lado, na CIDE-combustíveis, os recursos arrecadados serão destinados, dentre outros, ao financiamento de projetos ambientais relacionados com a indústria de petróleo e gás, conforme disposto no art. 177, II, “b”, CF. Ressalte-se, ainda, iniciativa do governo federal, que, por intermédio do Decreto no 7.619, de 21 de novembro de 2011, prevê que as empresas que utilizarem resíduos sólidos como matéria prima ou produtos intermediários na fabricação de seus produtos farão jus a crédito presumido do Imposto sobre Produtos Industrializados (IPI) na aquisição destes resíduos das cooperativas de catadores.

No Estado do Ceará, de acordo com a Lei no 15.086, de 28 de dezembro de 2011, ficam os produtos compostos por matéria-prima reciclada de resíduos sólidos passíveis de certificação do Selo Verde, para o gozo de benefícios e incentivos fiscais concedidos a contribuintes no Estado do Ceará, nos termos da legislação tributária específica. O Estado do Ceará concede, ainda, isenção do ICMS nas operaçôes com equipamentos e componentes destinados a usinas eólicas e solares, por exemplo, comprovando a forte extrafiscalidade deste imposto indireto que incide sobre o consumo.

A Lei no 12.305/2010, que instituiu a Política Nacional dos Resíduos Sólidos (PNRS), traz em seu art. $8^{\circ}$, inciso IX, como um de seus instrumentos "os incentivos fiscais, financeiros e creditícios”. Na mesma linha, a Lei no 12.187/2009, que cria a Política Nacional sobre Mudança do Clima, atenta às orientaçóes da Convenção Quadro das

59 Como é o caso do município de Campo Grande/MS, no qual foi instituído o IPTU Ecológico nos termos da Lei Complementar no 150, de 20 de janeiro de 2010. Disponível em: < http://contadez.cenofisco. com.br/legislacao.php?id=96938>. Acesso em 2 maio 13. 
Naçôes Unidas e do Protocolo de Quioto, aponta como uma de suas diretrizes, em seu art. 5 , inciso VII, "a utilização de instrumentos financeiros e econômicos para promover açôes de mitigação e adaptação à mudança do clima”.

Para se iniciar a defesa dessa tese, deve-se partir das diversas acepçóes do tributo, desenvolvidas por Paulo de Barros Carvalho, e que demonstram o largo espectro de atuação hermenêutica para a figura. Assim, o autor enuncia que o tributo poderia ser tomado como: (i) quantia em dinheiro; (ii) prestação correspondente ao dever jurídico do sujeito passivo; (iii) direito subjetivo de que é titular o sujeito ativo; (iv) sinônimo de relaçáo jurídico tributária; (v) norma jurídica tributária e (vi) norma, fato e relação. ${ }^{60}$

Após apresentá-las conjuntamente, identificando-lhes a abrangência, Carvalho tece críticas e comentários. Contudo, para o objeto do presente estudo, interessa especificamente a quinta acepção, a qual enquadra o tributo como norma jurídica, isto é, como preceito normativo ${ }^{61}$. Tal acepção é de fundamental importância neste trabalho, pois se trata daquela eleita pela $\mathrm{CF} / 88$, ao estabelecer as competências de cada um dos entes, nos art. 153, 155 e 156, ao identificar a tarefa de instituição do tributo como tarefa legislativa que se realiza com a edição das normas jurídicas correspondentes.

Assim, em um trabalho que se desenvolve a partir de um conceito constitucional de tributo, não se poderia pender, em um primeiro momento, para qualquer outra acepção. O que se depreende, então, é que a opção do legislador constituinte teria sido a de construir o seu próprio conceito de tributo, a partir de um sistema estruturado que impóe que as características tipológicas sejam colhidas nele mesmo, sendo a exação tributária utilizada como instrumento para potencializar as demais escolhas feitas no texto constitucional, e não apenas o ingresso de receitas públicas aos cofres dos entes tributantes.

Contudo, a opção por identificar o tributo como norma traz diversos complicadores, ou, para melhor dizer, torna ainda mais complexa a questão. Isto porque a norma é resultado da interpretação, não sendo correto identificá-la com os suportes físicos, isto é, com os textos de direito positivo. Adentrar no conceito de norma, como já se viu, significa optar pelo campo da hermenêutica jurídica ${ }^{62}$.

Nesse sentido, o conteúdo do direito positivo, que são as normas jurídicas, não são extraídos do substrato material do texto, mas construídos na forma de significações, na mente daquele que se propóe a interpretar tal substrato material. A norma jurídica, enquanto proposiçáo normativa ou deôntica, é tomada como um todo completo de

60 CARVALHO, op. cit., p. 51.

61 CARVALHO, op. cit., p. 55.

62 A hermenêutica jurídica, então, "é a Ciência que tem por objeto o estudo e a sistematização dos processos aplicáveis para construção e justificação do sentido dos textos do direito positivo". CARVALHO, Aurora Tomazini. Curso de Teoria Geral do Direito. Noeses: São Paulo, 2013, p. 223-224. 
significação o qual, faltando-se um elemento, desfaz-se. ${ }^{63}$ Nessa ordem, o suporte físico do direito é mero ponto de partida ${ }^{64}$, sendo o sentido, inesgotável ${ }^{65}$, posto que o palco de sua criação é o pensamento, o qual também é livre. ${ }^{66}$

Em tal ordem de ideias, a partir da identificação do direito enquanto sistema autopoiético, Gabriel Ivo identifica os dois momentos de construção das normas jurídicas realizados pelo homem: quando faz ingressar as normas por meio dos instrumentos indutores (os enunciados) e quando constrói a sua significação, a partir dos enunciados postos. ${ }^{67} \mathrm{O}$ Direito, então, regula e gera as suas próprias normas, em um movimento que tende ao infinito.

Além da inesgotabilidade dos sentidos, outro axioma da interpretação é a intertextualidade, que representa o intenso diálogo que os textos, sejam eles passados, presentes ou futuros, mantêm entre si, pouco importando as relaçóes de dependência entre eles. ${ }^{68} \mathrm{~A}$ partir daí, o princípio da subjetividade determinará as manifestações de cultura moderna ${ }^{69}$ e, pelo fato de o Direito ser um objeto cultural, não se vê afastado dessa subjetividade, a qual é ínsita ao processo interpretativo. ${ }^{70}$

A intertextualidade, ademais, aponta para o método de interpretação a ser adotado para a re(conceituação) do tributo. Nessa medida, seguindo a linha adotada por Paulo de Barros Carvalho, adotar-se-á o método sistemático, o qual aborda os planos sintático, semântico e pragmático da norma, e que pressupóe, também, os demais métodos de interpretação comumente aceitos pela Hermenêutica Jurídica tradicional (literal, lógico, histórico e teleológico). ${ }^{71}$

Com tudo isso, o que se pretende é uma re(conceituação) do tributo enquanto norma jurídica, a partir de sua concepção constitucional e, como tal, enaltecer a necessidade de se promover um diálogo a partir do Constructivismo Lógico-Semântico. Isso importa

63 VILANOVA, Lourival. As estruturas lógicas e o sistema de direito positivo. São Paulo: Noeses, 2010, p. 35.

64 CARVAlHO, Aurora Tomazini. Curso de Teoria Geral do Direito. Noeses: São Paulo, 2013, p. 226.

65 FALCÃO, Raimundo Bezerra. Hermenêutica. Malheiros: São Paulo, 2010, p. 94.

66 BELCHIOR, Germana Parente Neiva. Hermenêutica jurídica ambiental. São Paulo: Saraiva, 2011, p. 169.

67 IVO, Gabriel. Norma jurídica: Produçáo e controle. São Paulo: Noeses, 2006, p. 2.

68 CARVALHO, Paulo de Barros. Direito tributário, linguagem e método. Noeses: São Paulo, 2009, p. 194.

69 HABERMAS, Jünger. O discurso filosófico da modernidade. São Paulo: Martins Fontes, 2000, p. 26.

70 Deve-se fazer a ressalva de que toda essa tese há de se estruturar, ainda, com base na Teoria dos Valores, ou Axiologia, conforme desenvolvida por Johannes Hessen, Miguel Reale e Tércio Sampaio Ferraz Jr. Conforme ressalva Paulo de Barros Carvalho "o dado valorativo está presente em toda configuraçáo do jurídico, desde seus aspectos formais (lógicos), como nos planos semântico e pragmático”. CARVALHO, Paulo de Barros. Direito tributário, linguagem e método. Sáo Paulo: Noeses, p. 174.

71 CARVAlHO, Paulo de Barros. Curso de Direito Tributário. São Paulo: Saraiva, 2011, p. 134. 
na ampliação dos caracteres plasmados no CTN, confrontando-os as opçóes feitas pelo legislador ordinário quando da instituição de espécies tributárias que parecem distanciarse do hermetismo do art. $3^{\circ}$ do CTN.

\section{Conclusões}

A dinâmica estabelecida para enfrentar as complexidades das problemáticas oriundas dos efeitos deletérios de uma sociedade de consumo, pós-industrial e pós-moderna, nas quais os riscos estão marcados pelo traço da imprevisibilidade, tem gerado a necessidade de uma maior aproximação dos tradicionais ramos do Direito, notadamente, para a temática aqui disposta, entre o Direito Tributário e o Direito Ambiental.

Apesar de um relativo atraso na aprovação da Lei no 12.305/2010, comparativamente a outros países, tal Política Nacional dos Resíduos Sólidos (PNRS) não perde sua importância, uma vez que contempla institutos bastante diferenciados no direito positivo, podendo-se citar a logística reversa e a responsabilidade compartilhada pelo ciclo de vida dos produtos.

Diante dos mandamentos contidos na PNRS, destaca-se um dos instrumentos, configurado na possibilidade de concessão de incentivos fiscais, a serem utilizados para atingir os objetivos da política. Nesse contexto, ao Poder Público são ofertadas diversas possibilidades para que as finalidades da PNRS sejam atingidas.

Nesse cenário, viu-se que o Estado do Ceará, em conformidade com a PNRS, passou a prever incentivos fiscais de ICMS, ao incluir, na lista de seus produtos sujeitos à redução na base de cálculo, aqueles resultantes da utilização de materiais recicláveis, tais como plástico, papel, papeláo, resíduos da construção civil, dentre outros materiais.

A partir de tais disposiçóes, o Estado instituiu o Certificado do Selo Verde, a ser utilizado nos produtos que gozarão da redução na carga tributária. O fato é que tal medida favorece apenas as operaçóes internas ao Estado do Ceará, o que acaba por representar um parco alcance, ao ser comparado à abrangência que tal medida no âmbito nacional.

Em paralelo a isso, apesar da logística reversa ser um dos instrumentos inovadores da PNRS, sua operacionalização representa um custo a mais para as empresas brasileiras, o que acaba por desfavorecer uma mudança de atitude dos empresários.

Com isso, o que se propóe com o presente trabalho é que os Estados e o Distrito Federal debatam incentivos semelhantes ao Selo Verde cearense no âmbito do CONFAZ. O que se atestou é que, apesar da relevância da temática ambiental, e das possibilidades que a tributação favorece para alcançar objetivos outros que não a mera arrecadaçáo, ainda existe uma demora em se implementar os valores da PNRS. 


\section{Referências}

A riqueza que vem do lixo. Revista Exame PME. São Paulo: Abril, edição n. 72, p. 2241, abr. 2014.

ADAME MARTÍNEZ, Francisco. Tributos municipales sobre residuos en derecho comparado. In: SERRANO ANTÓN, Fernando (Coord.). Tributación ambiental y haciendas locales. Navarra: Aranzadi, 2011, p. 1025-1044.BAUMAN, Zygmunt. Modernidade líquida. Rio de Janeiro: Jorge Zahar, 2001.

BECK, Ulrich. A reinvenção da política: rumo a uma teoria da modernização reflexiva. In: BECK, Ulrich; GIDDENS, Anthony; LASH, Scott. Modernização Reflexiva: política, tradição e estética na ordem social moderna. São Paulo: UNESP, 1997, p. $11-68$

BOECHAT, Cláudio Bruzzi; CAMPOS, Paulo Március Silva; PEREIRA, André Luiz; SILVA, Jersone Tasso Moreira; TADEU, Hugo Ferreira Braga. Logística reversa e sustentabilidade. São Paulo: Cengage Learning, 2013.

BOWERSON, Donald J., CLOSS, Davis J. Logística empresarial. São Paulo: Atlas, 2001.

CARVALHO, Paulo de Barros. Direito Tributário: fundamentos jurídicos da incidência. São Paulo: Saraiva, 2012.

. Direito Tributário, linguagem e método. São Paulo: Noeses, 2009.

CAVALCANTE, Denise Lucena. Instrumentos fiscais na efetivação da Política Nacional de Resíduos Sólidos: do poluidor-pagador ao protetor-recebedor. In: CAVALCANTE, Denise Lucena (Coord.). Tributação ambiental: reflexos na Política Nacional de Resíduos Sólidos. Curitiba: CRV, 2014, p. 141-158.

COHEN, Miriam Alfie; SÁNCHEZ, Adrián de Garay. Risk society and the precautionary principle. In: BENIDICKSON, Jamie et al. Environmental law and sustainability after Rio. UK/USA: Edward Elgar Publishing Limited, 2011, p. 84-100.

GEORGESCU-ROEGEN, Nicholas. O decrescimento: entropia, ecologia, economia. Trad. Maria José Perillo Isaac. São Paulo: SENAC, 2012.

GUIVANT, Julia S. A teoria da sociedade de risco de Ulrich Beck: entre o diagnóstico e a profecia. In: Revista Estudos Sociedade e Agricultura. Vol. 16. Abr, 2001, p. 95-112. Disponível em: <http://bibliotecavirtual.clacso.org.ar/ar/libros/brasil/cpda/ estudos/ dezesseis/julia16.htm>. Acesso em: 20 jul. 2014.

LEITE, José Rubens Morato. Estado de Direito do Ambiente: uma difícil tarefa. In: Inovaçóes em Direito Ambiental. LEITE, José Rubens Morato (org.). Florianópolis: Fundação Boiteaux, 2000. 
LEITE, Paulo Roberto. Logística reversa - meio ambiente e competitividade. São Paulo: Pearson Prentice-Hall, 2006.

MAIMON, Dália. Eco-estratégia nas empresas brasileiras: realidade ou discurso. In: Revista de Administração de Empresas. Vol. 34, n. 4, Jul/Ago, 1994, p. 119-130. Disponível em: <http://rae.fgv.br/sites/rae.fgv.br/files/artigos/10.1590_S003475901994000400013.pdf>. Acesso em: 20 jul. 2014.

MORIN, Edgar. Os sete saberes necessários à educaçáo. São Paulo: Cortez- UNESCO, 2011.

NOLTE, Manfred. Fiscalidad y desarrollo humano sostenible. In: URIA GUTIÉRREZ, AITANA. De la economía verde a las sociedades verdes: reflexiones para el futuro que queremos. Madrid: Catarata, 2013, p. 102-119.

ROSEMBUJ, Tulio. El impuesto ambiental. Barcelona: El fisco, 2006.

SOLER, Fabricio Dourado; MACHADO FILHO, José Valverde; LEMOS, Patrícia Faga Iglecias. Acordos setoriais, regulamentos e termos de compromisso. In: JARDIM, Arnaldo; YOSHIDA, Consuelo; MACHADO FILHO, José Valverde. Política nacional, gestão e gerenciamento de resíduos sólidos. São Paulo: Manole, 2012, p. 79-101.

TANURO, Daniel. El imposible capitalismo verde: del vuelco climático capitalista a la alternativa ecosocialista. Madrid: La Oveja Roja, 2011. 